\title{
CALCULATION OF SHOCK STAND-OFF DisTANCE FOR A SPHERE IN NONEQUILIBRIUM HYPERSONIC FLOW
}

\author{
M. Ahn Furudate* \\ Dept. of Mechatronics Engineering, Chungnam Nat'l Univ. \\ 비평형 극음속 유동에서 구에 대한 충격파 이탈거리 계산 \\ M. Ahn Furudate* \\ 충남대학교 메카트로닉스공학과
}

Hypersonic flowfields over a sphere is calculated by using a nonequilibrium flow solver. The flow solver features a two-temperature model and finite rate chemical reaction models to describe nonequilibrium thermochemical processes. For the purpose of validation, the calculated shock stand-off distance is compared with the experimental data which is measured in a ballistic range facility. The present nonequilibrium calculation well reproduced the experimental shock stand-off distance in the cases where the experimental flowfields are expected to be nearly equilibrium, as well as in the cases to be nonequilibrium flowfields in the velocity range 4000 to $5500 \mathrm{~m} / \mathrm{s}$.

Key Words : Hypersonic flow(극음속 유동), Nonequilibrium flow(비평형 유동), Shock stand-off distance(충격파 이탈 거리), Two-temperature model(2온도모델)

\section{NOMENCLATURE}

$k_{f} \quad=$ forward reaction rate, $\mathrm{m}^{3} / \mathrm{mole}-\mathrm{s}$

$k_{b}=$ backward reaction rate, $\mathrm{m}^{3} /$ mole-s or $\mathrm{m}^{6} / \mathrm{mole}^{2}$-s

$K_{e q} \quad=$ equilibrium constant, mole $/ \mathrm{m}^{3}$

$T=$ translational-rotational temperature, $\mathrm{K}$

$T_{a} \quad=$ reaction rate controlling temperature, $\mathrm{K}$

$T_{v} \quad=$ vibrational-electronic temperature, $\mathrm{K}$

$\theta_{D} \quad=$ characteristic reaction temperature, $\mathrm{K}$

\section{INTRODUCTION}

Thermal protection is one of the most important issues in designing hypersonic space vehicles. When entering into

Received: April 9, 2012, Revised: Actober 26, 2012,

Accepted: Actober 29, 2012.

* E-mail: furu@cnu.ac.kr

DOI http://dx.doi.org/10.6112/kscfe.2012.17.4.069

(C) KSCFE 2012
Earth's atmosphere at a hypersonic speed, a detached shock wave is developed ahead of the space vehicle. The air between the shock wave and the space vehicle is strongly compressed, and heated up to a temperature of several thousands, or even of a several ten thousands Kelvin. Producing such an extreme heating environment in the ground testing facilities is difficult and expensive. Therefore, computational fluid dynamics (CFD) analysis is necessary to predict the heat transfer rate to the body surface of the space vehicle.

For an accurate prediction of heat transfer rate, CFD codes need to include the so-called high temperature real-gas effects: thermal excitations and chemical reactions of the gas species. The thermal excitations and chemical reactions behind the shock wave change the thermodynamic properties of the gas in the shock layer, hence, the heat transfer rate. When the characteristic time of the flow and the thermochemical processes is comparable, the flowfield may be in thermochemical nonequilibrium[1]. The temperature and the chemical composition, which determine heat transfer rate, are changed according to the degree of nonequilibrium in the flowfield. CFD codes also need to consider such 
nonequilibrium effects by using a multiple temperature description and finite chemical reaction rates.

Validation of CFD codes for nonequilibrium hypersonic flow is conveniently performed by comparing shock stand-off distances for a sphere with experimental data[2]. The shock stand-off distance varies depending on the thermochemical state in the shock layer; from the longer limit distance in a perfect gas flow without any thermal excitation and chemical reactions, to the shorter limit distance in an equilibrium flow in which thermal excitation and chemical reactions reach equilibrium immediately behind the shock wave.

Shock stand-off distance for a sphere has been measured by many researchers in various experimental facilities. It is believed that the experimental data obtained in ballistic range facilities are most reliable because of the absence of uncertainties in test flow conditions. In 1970's, Lobb measured shock stand-off distances for a sphere flying at hypersonic velocity in a ballistic range[3]. The tested flight velocities are concentrated over $4000 \mathrm{~m} / \mathrm{s}$. For intermediate hypersonic regime of the flight velocities less than $4000 \mathrm{~m} / \mathrm{s}$, Nonaka et al. conducted the measurement of shock stand-off distances for a sphere in another ballistic range facility[4].

There are various previous studies that have attempted to validate their CFD methodologies for hypersonic flows by comparing the calculated shock stand-off distance with the experimental data of Lobb. Sawada et al. have validated their thermochemical equilibrium calculations for the hypersonic equilibrium flow regime[5]. Prakash et al. have validated their high order shock-fitting method for the two selected cases from the experimental conditions of Lobb; one is from frozen flow regime and the other from nonequilibrium flow regime[6]. Despite a number of previous studies, only few studies discuss the general validity of nonequilibrium thermochemical models in the various regimes of hypersonic flow from the perspective of shock stand-off distances.

In the author's previous study[7], shock stand-off distances for a sphere is calculated by a nonequilibrium flow solver in order to examine the behavior of Park's two-temperature model[8] in intermediate hypersonic flow regime at the velocity under $4000 \mathrm{~m} / \mathrm{s}$. The study concluded that the two-temperature model generally reproduces the experimental shock standoff distances of Nonaka, although seems to lose its accuracy when vibrational excitation occurs but chemical reaction are nearly frozen. For the further investigation on the validity of the two-temperature model of Park, it is needed to examine this model for the higher hypersonic flow over $4000 \mathrm{~m} / \mathrm{s}$.

The purpose of this study is to validate the two-temperature model in higher hypersonic flow over $4000 \mathrm{~m} / \mathrm{s}$. Hypersonic flowfields over a sphere is calculated using a nonequilibrium hypersonic flow solver. The calculated shock stand-off distances are compared with the ballistic range data by Lobb in order to clarify the limitation in validity of the two-temperature in higher hypersonic flow.

\section{Calculation methodology}

\subsection{GOVERNING EQUATIONS}

The governing equations are the two-dimensional axisymmetric Navier-Stokes equations. The set of equations consists of global mass, species mass, momentum, total energy, and vibrational-electronic energy conservation equations. Five neutral air species, i.e., $\mathrm{N}_{2}, \mathrm{O}_{2}, \mathrm{NO}, \mathrm{O}$ and $\mathrm{N}$ are considered.

\subsection{Chemical REACTION RATE MOdeL}

Following seventeen chemical reactions are considered, where $M$ stands for possible collision partners,

$$
\begin{array}{ll}
\mathrm{O}_{2}+M \rightleftharpoons \mathrm{O}+\mathrm{O}+M & \mathrm{R} 1 \\
\mathrm{~N}_{2}+M \rightleftharpoons \mathrm{N}+\mathrm{N}+M & \mathrm{R} 2 \\
\mathrm{NO}+M \rightleftharpoons \mathrm{N}+\mathrm{O}+M & \mathrm{R} 3 \\
\mathrm{~N} 2+\mathrm{O} \rightleftharpoons \mathrm{NO}+\mathrm{N} & \mathrm{R} 4 \\
\mathrm{NO}+\mathrm{O} \rightleftharpoons \mathrm{O}_{2}+\mathrm{N} & \mathrm{R} 5
\end{array}
$$

The forward reaction rates are written by the form,

$$
k_{f}\left(T_{a}\right)=C_{f} T_{a}^{\eta} \exp \left(-\theta_{D} / T_{a}\right)
$$

The reaction rate coefficients proposed for twotemperature model by Park[9] is employed, as given in Table 1. For the dissociation reactions, the rate controlling temperature is defined by,

$$
T_{a}=\sqrt{T T_{a}}
$$

and for the exchange and recombination reactions,

$$
T_{a}=T
$$

The backward reaction rates are written by the form, 


$$
k_{b}(T)=k_{f}(T) / K_{e q}(T)
$$

where

$$
K_{e q}=\exp \left(A_{1} Z+A_{2}+A_{3} \ln (1 / Z)+A_{4} / Z+A_{5} / Z^{2}\right)
$$

and

$$
Z=10,000 / T
$$

The coefficients for the equilibrium constants in Eq. (5) are given in Table 2. In order to account for the fact that dissociation reactions occur from higher energy level, a preferential dissociation model is employed. The removed or gained vibrational energy through the dissociation or recombination reactions are set to $30 \%$ of the corresponding dissociation energy, according to Sharma's suggestion[10].

\subsection{Transport coefficients}

The molecular viscosity for air species is given by Blottner's model[11] and the thermal conductivity by Eucken's relation[12]. Those transport properties for air are obtained from Wilke's empirical mixing formula[13]. The diffusion coefficients are assumed to be constant for all species with a constant Schmitt number 0.5.

\subsection{Numerical methods}

The numerical scheme is based on the cell-centered Table 1 Forward reaction rate coefficients[9]

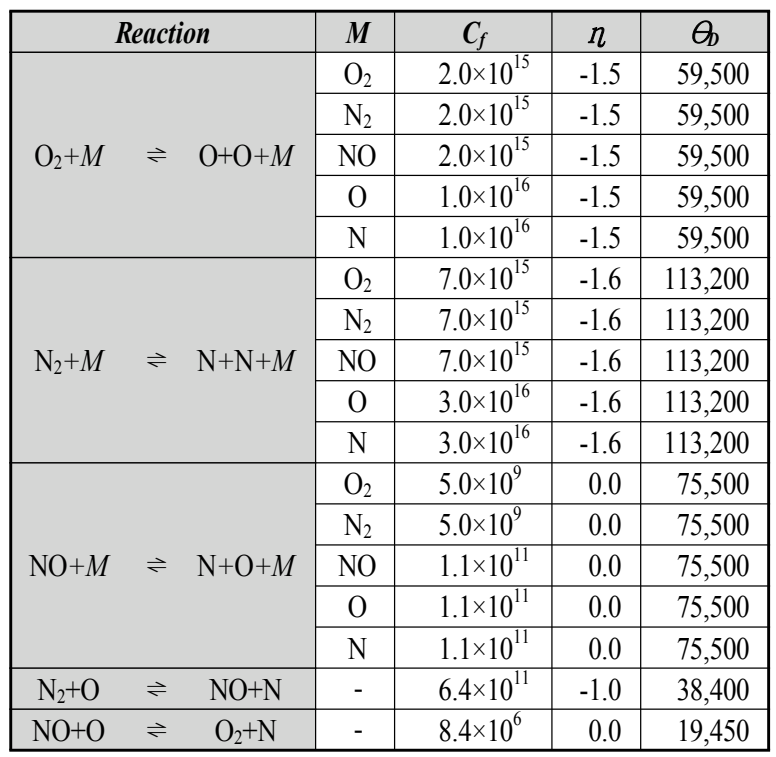

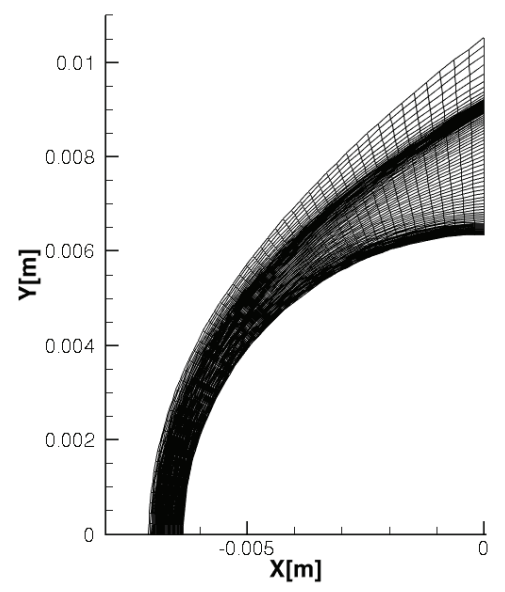

Fig. 1 Example of computational mesh system $(51 \times 101)$

finite volume discretization. The convective numerical flux is calculated by AUSM-DV upwind scheme[14]. The MUSCL approach is employed for the higher spatial accuracy. For time integration, LU-SGS implicit method is used. For the convergence acceleration, the local time stepping method is employed.

\section{TEST CONDITIONS}

Calculations of the flowfield over a sphere are carried out for the conditions corresponding to the ballistic range experiments of Lobb. The nose radius of the sphere is $6.35 \mathrm{~mm}$. Four static pressure conditions are taken from the experimental conditions, i.e., 2.5, 5.0, 10, and 20 $\mathrm{mmHg}$. For each pressure condition, the flight velocity is varied from 4000 to $6400 \mathrm{~m} / \mathrm{s}$. The temperature in the test section is $293 \mathrm{~K}$. Test gas is air consisting of $23.3 \%$ of $\mathrm{O}_{2}$ and $76.7 \%$ of $\mathrm{N}_{2}$ by mass. The projectile is assumed to have an isothermal fully-catalytic wall of $1000 \mathrm{~K}$. Wall temperature and wall catalysis are important factors to determine a heat transfer rate to the body surface. Hence, they should be carefully modeled in the numerical analysis for thermal protection system design. However, in terms of shock stand-off distance or shock shapes, effects of such wall conditions are less significant, as shown in the

Table 2 Constants for equilibrium constants[9]

\begin{tabular}{|c|l|l|l|c|c|}
\hline Reaction & \multicolumn{1}{|c|}{$\boldsymbol{A}_{\boldsymbol{I}}$} & \multicolumn{1}{c|}{$\boldsymbol{A}_{2}$} & \multicolumn{1}{c|}{$\boldsymbol{A}_{3}$} & $\boldsymbol{A}_{4}$ & $\boldsymbol{A}_{5}$ \\
\hline 1 & 0.553880 & 16.275511 & 1.776300 & -6.57200 & 0.031445 \\
\hline 2 & 1.53510 & 15.4216 & 1.2993 & -11.494 & -0.00698 \\
\hline 3 & 0.558890 & 14.53108 & 0.553960 & -7.53040 & -0.014089 \\
\hline 4 & 0.976460 & 0.890430 & 0.745720 & -3.96420 & 0.007123 \\
\hline 5 & 0.004815 & -1.74430 & -1.22270 & -0.95824 & -0.045545 \\
\hline
\end{tabular}




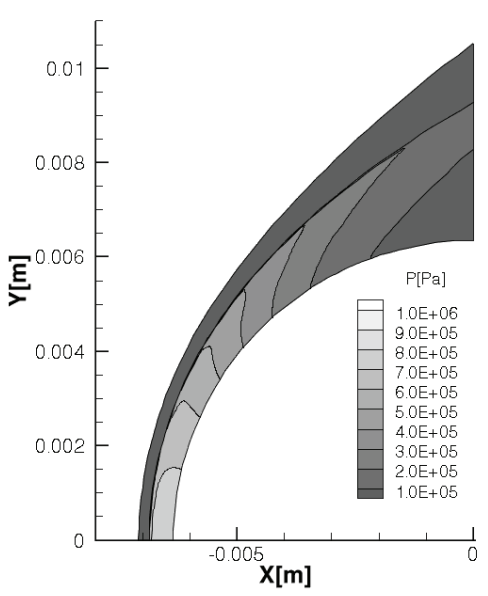

Fig. 2 Calculated pressure contour $(p=20 \mathrm{mmHg}, 6000 \mathrm{~m} / \mathrm{s})$

author's previous study in Ref. 15. Fig. 1 shows a typical structured mesh system used in the calculations. The number of mesh points is 51 along the wall and 101 in the direction normal to the wall.

\section{Results and Discussions}

A typical pressure contours obtained in the present calculation is shown in Fig. 2. The shock wave developed ahead of the sphere is clearly captured in the calculation. Shock stand-off distance in the present study is defined by the distance between the wall surface and the shock wave in the stagnation streamline. The shock wave position is determined by the point having the maximum pressure gradient.

The calculated shock stand-off distances are compared with the experimental data of Lobb in Fig. 3. The closed symbols indicate the results of the present calculations, and the open symbols the experimental data of Lobb. The solid line shows the theoretical values of shock stand-off distance under the assumption of perfect gas. The dashed and the doted lines are the values of equilibrium calculations. The experimental data of Lobb are distributed between these perfect gas line and the equilibrium lines. Generally, the thermochemical regimes of the flowfields in the shock layer change from frozen to equilibrium when the static pressure varies from high to low, as well as when the flight velocity varies from low to high. These tendencies are clearly seen in the experimental data of Lobb. At the lowest static pressure condition of $p=2.5$ $\mathrm{mmHg}$ in Fig. 3a, the experimental data of Lobb are distributed in the middle range between the perfect gas

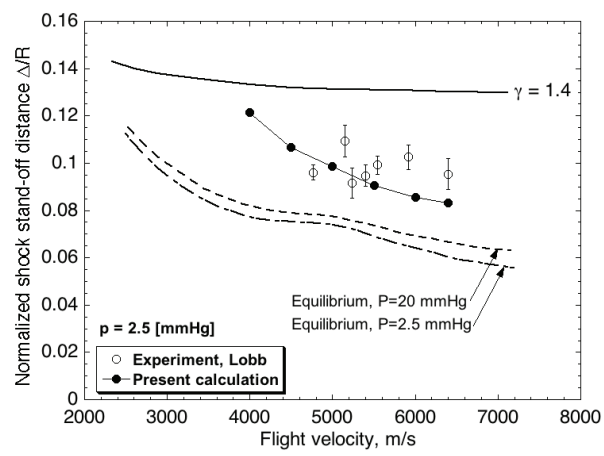

(a) $p=2.5 \mathrm{mmHg}$

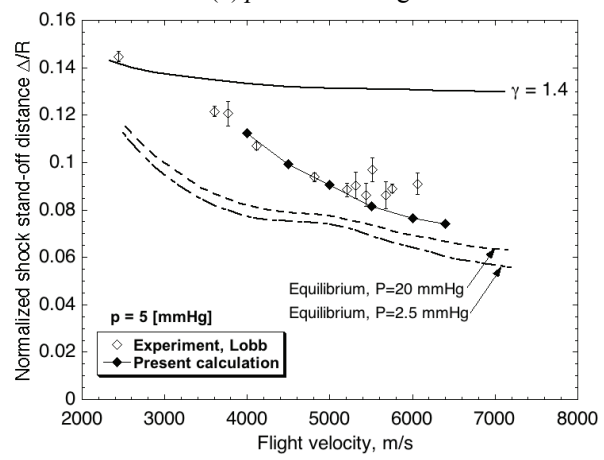

(b) $p=5 \mathrm{mmHg}$

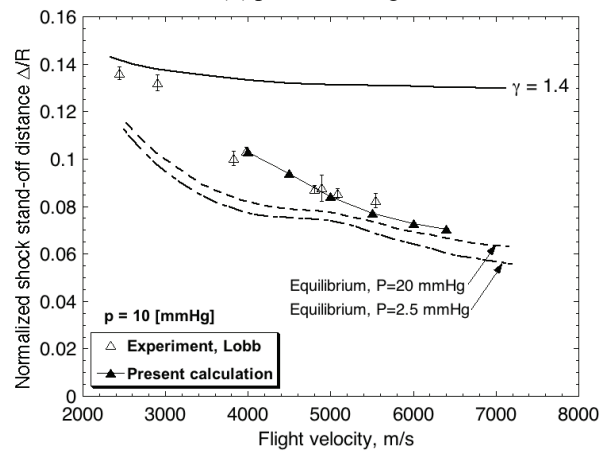

(c) $p=10 \mathrm{mmHg}$

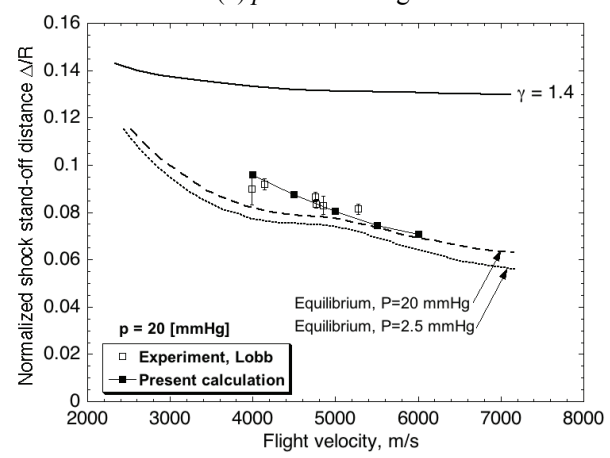

(d) $p=20 \mathrm{mmHg}$

Fig. 3 Comparison of shock stand-off distances for sphere between the two-temperature calculations and the ballistic range data 

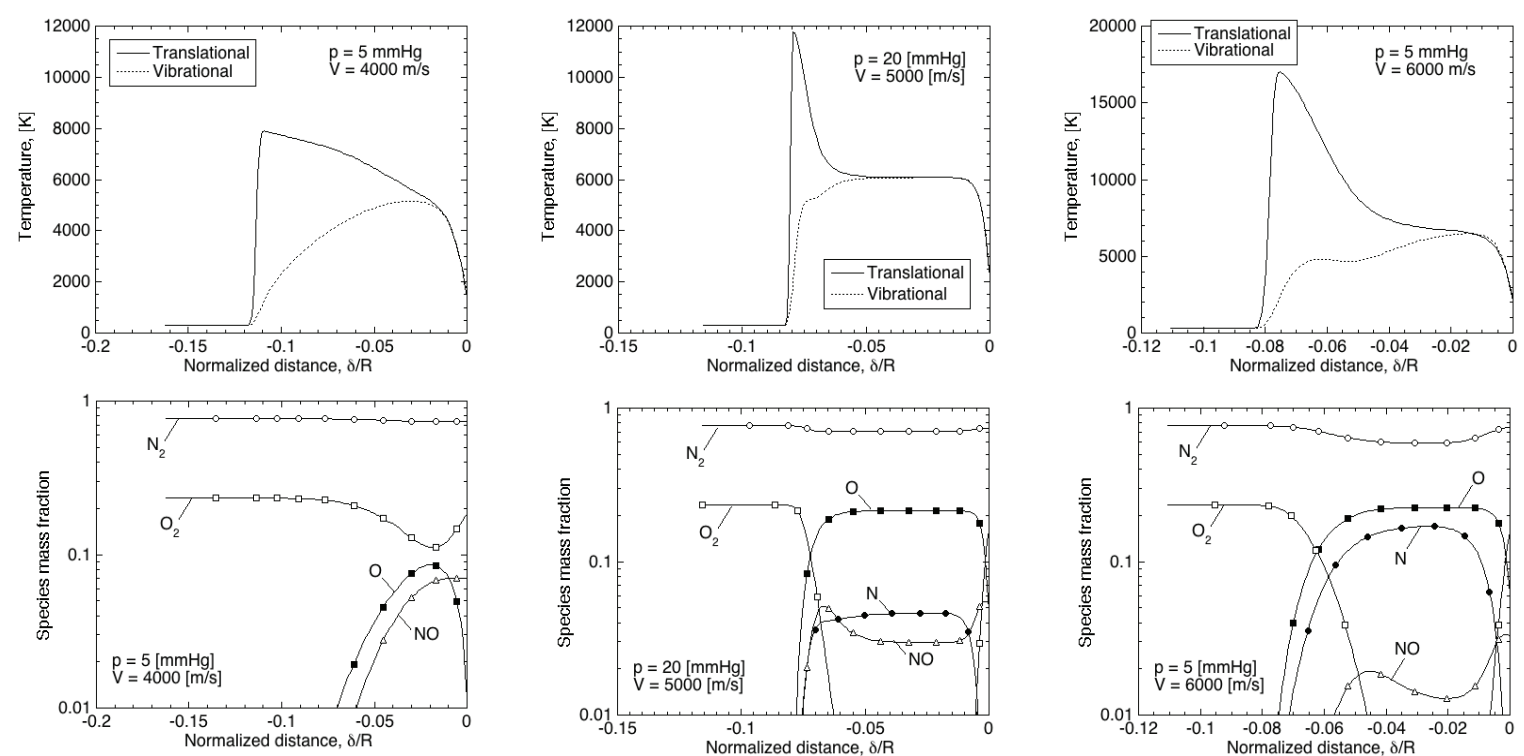

(a) $\mathrm{p}=5 \mathrm{mmHg}$ and $\mathrm{V}=4000 \mathrm{~m} / \mathrm{s}$

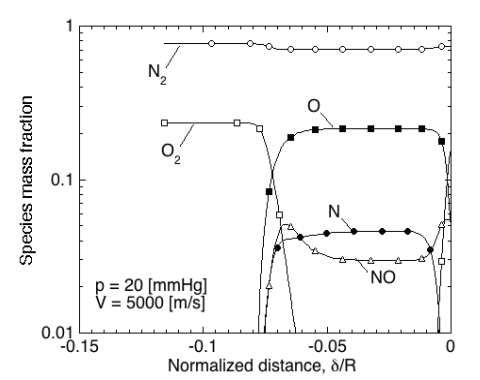

(b) $\mathrm{p}=20 \mathrm{mmHg}$ and $\mathrm{V}=5000 \mathrm{~m} / \mathrm{s}$

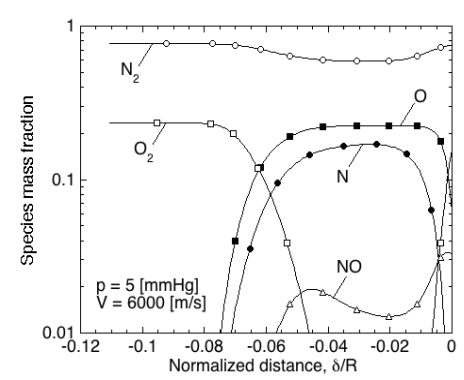

(c) $\mathrm{p}=5 \mathrm{mmHg}$ and $\mathrm{V}=6000 \mathrm{~m} / \mathrm{s}$

Fig. 4 Calculated temperatures and species mass fraction profiles along the stagnation streamline

line and the equilibrium lines, indicating that the flowfields around the projectile are in thermochemical nonequilibrium. At the highest static pressure condition of $\mathrm{p}=20 \mathrm{mmHg}$ in Fig. $3 \mathrm{~d}$, the experimental data are distributed close to the equilibrium calculation line, indicating the flowfields are nearly in thermochemical equilibrium.

As shown in Figs. 3c and 3d, the calculated shock stand-off distances agree well with the experimental data of $\mathrm{p}=10$ and $20 \mathrm{mmHg}$, where the flowfields are expected to be nearly in thermochemical equilibrium. At the static pressure cases of $\mathrm{p}=2.5$ and $5 \mathrm{mmHg}$ in Figs. $3 \mathrm{a}$ and $3 \mathrm{~b}$, the experimental data of shock stand-off distance in the flight velocity range from 4000 to 5500 $\mathrm{m} / \mathrm{s}$. However, for the flight velocity range over $5500 \mathrm{~m} / \mathrm{s}$, the calculated stand-off distances tend to be shorter than the experimental data, as shown in Fig. 3a and $3 b$.

Fig. $4 \mathrm{a}$ and $4 \mathrm{~b}$ show the calculated temperature and the mass fraction profile along the stagnation streamlines for two selected cases, that is, the case of $p=5 \mathrm{mmHg}$ and $V=4000 \mathrm{~m} / \mathrm{s}$ as a lower pressure and lower velocity case, and of $p=20 \mathrm{mmHg}$ and $V=5000 \mathrm{~m} / \mathrm{s}$ as a higher pressure and higher velocity case. For these two cases, the calculated shock stand-off distances agree well with the experimental data. In the lower pressure and lower velocity case in Fig. 4a, the vibrational temperature rises slowly compared to the translational temperature behind the shock wave, indicating a thermally nonequilibrium flowfield. A certain amount of atomic oxygen is produced due to dissociation in the shock layer closer to the body surface. Nitric oxide is also produced as a result of the exchange reaction between atomic oxygen and molecular nitrogen, R4. Atomic nitrogen produced by R4 seems to be consumed by the exchange reaction to form nitric oxide through the backward reaction of R5. In the higher pressure and higher velocity case in Fig. 4b, equilibrium between the translational and the vibrational temperatures are attained in the shock layer. The flat plateaus in the species mass fraction profiles in the shock layer indicate that the flowfield is also chemically equilibrium. Molecular oxygen is almost completely dissociated in the shock layer. A certain amount of atomic nitrogen also presents in the shock layer, which are mostly produced by the reactions R3 and R4 rather than the dissociation of molecular nitrogen R2.

The flowfield for the case of $p=5 \mathrm{mmHg}$ and $V=$ $6000 \mathrm{~m} / \mathrm{s}$ is now examined, in which the calculated shock stand-off distance is smaller than the experimental data. The temperature and the species mass fraction profiles obtained in the present calculation are shown in Fig. 4c. The translational temperature immediately behind the shock wave is as high as $17,000 \mathrm{~K}$, resulting in immediate dissociation of molecular oxygen. By the effect of preferential dissociation, the vibrational temperature behind 
the shock layer stays at the value of about $5000 \mathrm{~K}$, where the dissociation of molecular oxygen is proceeding. The thermal equilibrium is attained only near the boundary layer. A significant amount of atomic nitrogen is produced due to dissociation of nitric oxygen, R4. If the one-temperature model is adopted for this case, which assumes thermal equilibrium between translational and vibrational modes, the shock stand-off distance is expected to be shorter than in the two-temperature calculation due to the lowered translational temperature in the shock layer.

These results show that the present nonequilibrium calculation generally well reproduce the experimental data of shock stand-off distance in nonequilibrium flow regime to equilibrium flow regime. However, in lower pressure and higher velocity cases, the calculated shock stand-off distances tend to be shorter than the experimental data. In such cases, molecular oxygen is completely dissociated, and nitric oxide is dissociating. Furthermore, there are considerable discrepancies between the experimental data obtained by Lobb and by Nonaka in the intermediate hypersonic flow of less than $4000 \mathrm{~m} / \mathrm{s}$. There still exists a room for further investigations and discussions on validity of nonequilibrium calculations using the two-temperature model.

\section{CONCLUSIONS REMARK}

Hypersonic flowfields over a sphere at the velocity range from 4000 to $6400 \mathrm{~m} / \mathrm{s}$ are calculated by a nonequilibrium flow solver, in order to validate the two-temperature model in higher hypersonic flow. The calculated shock stand-off distance is compared with the experimental data of Lobb which is measured in a ballistic range facility. It is found that the two temperature model of Park well reproduces the experimental shock stand-off distances of Lobb at the flight velocities between 4000 and $5500 \mathrm{~m} / \mathrm{s}$. At the flight velocities over $5500 \mathrm{~m} / \mathrm{s}$, the two-temperature calculation predicts stand-off distance shorter than the experimental data.

\section{ACKNOWLEDGEMENT}

This study was financially supported by research fund of Chungnam National University in 2010.

\section{REFERENCES}

[1] 1989, Anderson, J. D., Jr., Hypersonic and High Temperature Gas Dynamics, McGraw - Hill, New
York

[2] 1997, Park, C., "Validation of CFD codes for real-gas regime," AIAA-1997-2530.

[3] 1964, Lobb, K., "Experimental Measurement of Shock Detachment Distance on Sphere Fired in Air at Hypervelocities," The High Temperature Aspect of Hypersonic Flow, edited by W. C. Nelson, Macmillan, New York.

[4] 1997, Nonaka, S., and Takayama, K., "Measurement of Shock Standoff Distance for Sphere in Ballistic Range," AIAA Paper 97-0563.

[5] 2001, Sawada, K., and Dendou, E, "Validation of hypersonic chemical equilibrium, flow calculations using ballistic-range data," Shock Waves, Vol.11, pp.43 $-51$.

[6] 2011, Prakash, A., Parsons, N., Wang, X., and Zhong, $\mathrm{X}$, "High-order shock-fitting methods for direct numerical simulation of hypersonic flow with chemical and thermal nonequilibrium," Journal of Computational Physics, Vol.230, pp.8474 - 8507.

[7] 1999, Furudate, M., Nonaka, S. and Sawada, K., "Behavior of Two-Temperature Model in Intermediate Hypersonic Regime," Journal of Thermophysics and Heat Transfer, Vol.13, No.4, pp.424-430.

[8] Park, C., "Assessment of Two-Temperature Kinetic Model for Ionizing Air," Journal of Thermophysics and Heat Transfer, Vol.3, pp.233-244, 1989.

[9] 1989, Park, C., Nonequilibrium Hypersonic Aerothrmodynamics, John Wiley and Sons Inc., New York.

[10] 1988, Sharma, S. P., Hou, W., and Park,C., "The Rate Parameter for Coupled Vibration-Dissociation in Generalized SSH Theory," AIAA Paper 88-2714.

[11] 1971, Blottner, F.G., Johnson, M., and Ellis, M., "Chemically Reacting Viscous Flow Program for Multi-Component Gas Mixture," Report No. SC-RR70-754, Sandia Laboratories.

[12] Vincenti, W. G., and Kruger, C. H., Introduction to Physical Gas Dynamics, John Wiley and Sons Inc., New York, 1967.

[13] 1950, Wilke, C.R., "A Viscosity Equation for Gas Mixtures," Journal of Chemical Physics, Vol.18, pp.517-519.

[14] 1994, Wada, Y. and Liu, M. S., "A Flux Splitting Scheme with High-Resolution and Robustness for Discontinuities," AIAA Paper 94-0083.

[15] 2003, Furudate, M., Nonak, S., and Sawada., K., "Calculation of Shock Shapes over Sharp Cone in Intermediate Hypersonic Airflow," Journal of Thermophysics and Heat Transfer, vol.17, pp.250-258. 